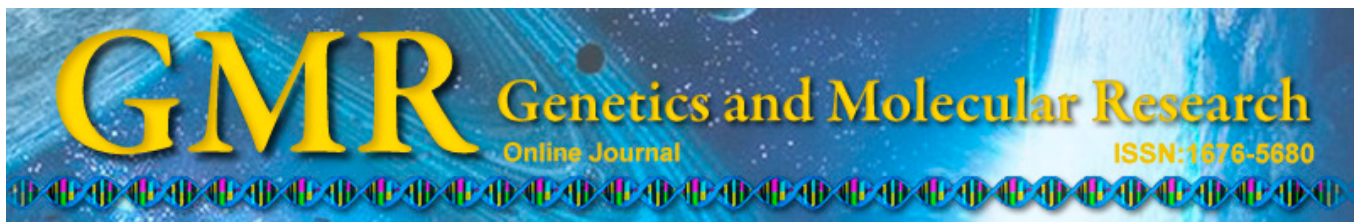

\title{
Activin A is associated with asthma in underweight and overweight patients
}

\author{
L.L. Zhang and C.T. Liu \\ Department of Respiration Medicine, West China Hospital, \\ Sichuan University \\ Corresponding author: C.T. Liu \\ E-mail: taosen666@vip.tom.com
}

Genet. Mol. Res. 14 (1): 440-452 (2015)

Received November 28, 2013

Accepted September 7, 2014

Published January 23, 2015

DOI http://dx.doi.org/10.4238/2015.January.23.18

\begin{abstract}
There are limited data regarding the effects of activin A on underweight, normal weight, and overweight patients with asthma. We determined serum levels of activin $\mathrm{A}$ in asthmatic patients in relation to body mass index. The study protocol included questionnaires, measurement of exhaled nitric oxide, blood sampling for inflammatory biomarkers, and high-resolution computed tomography of the lungs to identify bronchial wall thickening. Serum and sputum activin A levels were measured using an enzyme-linked immunosorbent assay in 94 asthmatic patients. Mean serum levels of activin A were significantly $(\mathrm{P}=0.001)$ higher in underweight $(1781 \pm 327.3 \mathrm{pg} / \mathrm{mL})$ than in normal weight and overweight asthmatic patients, regardless of gender. After stratification by gender, significantly higher mean values of activin A were observed in females compared to males in the normal and underweight groups $(\mathrm{P}=0.003$ and $\mathrm{P}=0.0002$, respectively). Significant differences between groups were found in airway wall area $(\%)(\mathrm{P}<0.0001)$. We also observed a much higher percentage of sputum lymphocytes in the underweight group compared to the other groups $(\mathrm{P}<0.0001)$. Correlations between bronchial wall thickness and activin $\mathrm{A}$ were found in the underweight $(\mathrm{r}=0.67, \mathrm{P}=0.48)$ and normal weight groups $(\mathrm{r}=0.51, \mathrm{P}=0.042)$. Correlations between fractional of
\end{abstract}


exhaled nitric oxide, forced expiratory volume in $1 \mathrm{~s}$, delayed treatment years, and activin A in different groups were also observed. Increased serum level of activin A indicates its role in the pathogenesis of asthma, particularly in underweight and overweight patients.

Key words: Activin A; Asthma; Overweight; Underweight

\section{INTRODUCTION}

As the prevalence of obesity increases worldwide (Flegal et al., 2002; Hedley et al., 2004), concern regarding the association between body weight and higher mortality rates has also increased. Additionally, the increasing prevalence of asthma and obesity suggests an association between these diseases (Beuther et al., 2006). Although asthma is less prevalent than being overweight, asthma affects approximately $7 \%$ of the adult population in the United States (Pleis et al., 2009).

Many cross-sectional epidemiologic studies have identified a modest association between obesity and asthma prevalence (Chen et al., 1999; Beckett et al., 2001; Guerra et al., 2002). Beuther et al. (2006) compared normal weight, overweight, and obese subjects (body mass index, BMI $\geq 25$ ) and found an increased odds of incident asthma, with an odds ratio of 1.51 .

Activin A is a pleiotropic cytokine that belongs to the transforming growth factor- $\beta$ superfamily and plays a critical role in fundamental biological processes, such as development and tissue repair. Although the exact function of activin A remains uncertain, it also functions to modulate inflammatory responses (Jones et al., 2007), and growing evidence indicates a crucial role of activin-A in immune-mediated responses and associated diseases, while also activating tissue repair programs (Sulyok et al., 2004). Activin A has a unique role in key biological processes (Xia and Schneyer, 2009), and may play a role in airway remodeling by inducing structural changes. Moreover, recent advances underscore the critical impact of activin A on T helper type 2 cell-driven airway inflammation and associated asthmatic diseases (Samitas et al., 2012; Tousa et al., 2012). However, whether activin A is correlated with BMI in asthmatic patients remains unknown.

\section{MATERIAL AND METHODS}

The study group was comprised of randomly selected asthma patients from 215 asthmatics who visited the outpatient clinics in West China Hospital of Sichuan University between January 2012 and March 2013. The study was approved by the Ethics Committee of the West China Hospital of Sichuan University and written informed consent was obtained from all patients.

\section{Study design and treatment}

This was a cohort study to compare airway inflammation as assessed by induced sputum and fraction of exhaled nitric oxide (FENO) in subjects with asthma. Induced sputum and exhaled NO were collected on the same day. All subjects were adult nonsmokers or ex-smokers for at least 5 years and with a smoking history of less than 10 pack-years, 18 years of age or older with asthma, a 20\% fall in forced expiratory volume in $1 \mathrm{~s}$ (FEV1) during a histamine 
challenge test, and showing clinical symptoms of asthma according to current American Thoracic Society (ATS, 1987) criteria. A questionnaire on respiratory symptoms, lung function test, histamine challenge test, blood test, and induced sputum was administered.

Exclusion criteria included the presence of specific respiratory disease or any other serious interfering disease. Patients were required to be in stable condition without an exacerbation in the previous 6 weeks. Patients with chronic obstructive pulmonary disorder or a $>30$ pack-year history of smoking were also excluded. FENO was measured using a chemiluminescence analyzer (NiOX; Aerocrine, Stockholm, Sweden) before forced expiratory maneuvers according to current guidelines at an exhaled flow rate of $50 \mathrm{~mL} / \mathrm{s}$.

\section{Procedures}

Spirometry was performed according to the ATS standards (Miller et al., 2005). Sputum was induced using inhalations of increasing concentrations $(3,4$, and $5 \%)$ of hypertonic saline and processed as previously described. All slides were read at the same center. FENO was collected by using a validated offline technique with sample bags in accordance with the ATS recommendations.

\section{High-resolution computed tomography (HRCT) scan}

Prior to HRCT, all patients were shown how to breathe during the scanning procedure. HRCT was performed using a multi-detector row spiral CT scanner (Sensation 16, Siemens Medical System, Erlangen, Germany) with 16 detector arrays. Patients were scanned in the supine position during 1 breath hold at deep inspiration. Scanning was performed at $120 \mathrm{kV}$ and 80 $\mathrm{mAs}$, regardless of patient size, using a 512 × 512 matrix. Scans were obtained using 16 x $1 \mathrm{~mm}$ collimation at $10-\mathrm{mm}$ intervals, with a table field of $11 \mathrm{~mm}$ per $0.5 \mathrm{~s}$ scanner rotation. Images were reconstructed using a bone algorithm and a 512 x 512 matrix. Images were viewed in a window level of -450 Hounsfield units and a width of 1500 Hounsfield units. CT scans were interpreted by 2 radiologists (Zhang, Yang) who were unaware of the clinical history of the patients.

Bronchial wall thickening (BWT) was assessed as follows. End-expiratory scans were obtained at 5 selected levels: $1 \mathrm{~cm}$ above the carina (Level A), $1 \mathrm{~cm}$ below the carina (Level $\mathrm{B}$ ), the right pulmonary vein (Level C), $3 \mathrm{~cm}$ below the top of the pulmonary vein (Level D), and above the right side of the diaphragm (Level E) (King et al., 2000). BWT at these 5 levels was measured. The following parameters were determined using a semiautomatic image-processing program: luminal area, total airway area, short axis of lumen, and short axis of total airway. Airway wall area (WA) was calculated as total airway area - luminal area and BWT was calculated as (short axis of total airway - short axis of lumen) / 2. Relative WA $[\mathrm{WA} \%=(\mathrm{WA} /$ total airway area $) \times 100]$ was also calculated.

\section{Measurement of serum and induced sputum activin A levels}

Serum YKL-40 levels were measured using an enzyme-linked immunosorbent assay (ELISA) kit according to manufacturer instructions (Human Chitinase 3-like 1 DuoSet ELISA Development Kit, RnD Systems, Abingdon, UK). Activin A levels were measured in duplicate using commercially available ELISA kits for activin A (Quidel, San Diego, CA, USA). Means $\pm \mathrm{SD}$ values are reported. Sputum induction and processing were performed according to $\mathrm{Pa}$ - 
vord et al. (1997). Briefly, prior to sputum induction, in order to decrease bronchi-construction during the induction procedure, asthmatic patients were advised to inhale $400 \mathrm{mg}$ Salbutamol, sputum was induced by inhalation of nebulized hypertonic saline solution (3\%) for 15 $\mathrm{min}$, and then patients were encouraged to expectorate sputum. All adequate plugs of sputum were separated from saliva and mixed with an equal volume (to dithiothreitol) of Dulbecco's phosphate-buffered saline. After centrifugation, differential cell counts were determined by counting 400 non-squamous cells (eosinophils, macrophages, lymphocytes, and neutrophils counts) in the stained specimens.

\section{Anthropometric measurements}

According to federal guidelines (NHLBI, 1998), being underweight for adults is defined as a BMI less than 18.5, normal weight as a BMI from 18.5 to less than 25, overweight as a BMI 25 to less than 30 , and obesity as a BMI of 30 or greater. However, obesity is not prevalent in China, and thus we did not calculate this group.

\section{Statistical analysis}

A comparison of the characteristics of patients with underweight, normal weight, and overweight was first performed using one-way analysis of variance for normal distributions, the Kruskal-Wallis test for non-normal distributions, or the $\chi^{2}$ test for categorical variables. If these tests indicated a difference between the 3 groups, group-by-group comparisons were performed using the Student $t$-test, the Mann-Whitney U-test, or the $\chi^{2}$ test as appropriate. Sputum and bronchial cell counts as well as exhaled NO data were analyzed after logarithmic transformation. To identify associations between FEV1 and FENO, nonparametric correlation analysis (Spearman rank test) was used. These tests were also used to compare the characteristics of patients with FENO and biological markers in induced sputum.

\section{RESULTS}

The characteristics of the 94 subjects with asthma are presented in Table 1. Both groups were similar with regard to age. Among asthma patients studied, 24 (18 females and 6 males) were overweight (BMI < 18.5), 40 (32 females and 8 males) were of normal weight (BMI 18.5-25), and 30 (18 females and 12 males) were overweight (BMI $\geq 25$ ). The mean values of immunoglobulin E and FEV1/forced vital capacity (\%) in asthmatics did not differ from mean values determined for each group. Mean values of FENO, FEV1 (L predicted), and peak expiratory flow in all groups showed significant differences.

The mean values of activin A serum levels in all patients are shown in Figure 1. Mean serum levels of activin A were significantly $(\mathrm{P}=0.001)$ higher in underweight $(1781 \pm 327.3$ $\mathrm{pg} / \mathrm{mL})$ than in both normal weight asthmatic patients $(888.9 \pm 799.3 \mathrm{pg} / \mathrm{mL})$ and overweight asthmatic patients $(714.0 \pm 639.3 \mathrm{pg} / \mathrm{mL})$, regardless of gender. After stratification by gender, mean activin $\mathrm{A}$ concentration $(\mathrm{P}=0.70)$ was not higher in underweight female subjects (1748 $\pm 88.86 \mathrm{pg} / \mathrm{mL}, \mathrm{N}=18)$ compared to male subjects $(1669 \pm 182.0 \mathrm{pg} / \mathrm{mL}, \mathrm{N}=6)$. In the normal weight group, significantly higher $(\mathrm{P}=0.003)$ mean values of activin $\mathrm{A}(840.7 \pm 142.1 \mathrm{pg} /$ $\mathrm{mL}, \mathrm{N}=32)$ were observed in female subjects compared to male subjects $(320.0 \pm 77.98 \mathrm{pg} /$ $\mathrm{mL}, \mathrm{N}=8)$. In overweight group, significantly higher $(\mathrm{P}=0.0002)$ mean values of activin $\mathrm{A}$ levels $(1405 \pm 178.3 \mathrm{pg} / \mathrm{mL}, \mathrm{N}=18)$ were observed in female subjects compared to male sub- 
jects $(515.0 \pm 100.3 \mathrm{pg} / \mathrm{mL}, \mathrm{N}=12)$. There was a significantly higher mean activin A concentration $(\mathrm{P}=0.0001)$ in the underweight female group $(1748 \pm 377.0 \mathrm{pg} / \mathrm{mL})$ and overweight female group $(1405 \pm 756.4 \mathrm{pg} / \mathrm{mL})$ compared to females in the normal weight group $(840.7 \pm$ $803.7 \mathrm{pg} / \mathrm{mL})$. In underweight males, significantly higher $(\mathrm{P}<0.0001)$ mean values of activin A were observed compared to normal weight and overweight subjects $(320.0 \pm 220.6 \mathrm{pg} / \mathrm{mL}$ and $515.0 \pm 347.3 \mathrm{pg} / \mathrm{mL}$, respectively).

We also identified an association between delayed treatment years and activin $\mathrm{A}$ in underweight patients $(r=-0.43, P=0.03)$. However, we did not observe an association between delayed treatment years and activin A in normal weight, overweight, and all group patients (Figure 2).

Compared with each group, we found that exacerbations in the past 2 years occurred more frequently in the overweight group compared to other groups $(\mathrm{P}=0.027)$ (Figure 3$)$.

Negative associations between asthma control test (ACT) scores and activin A were observed in all subjects $(r=-0.34, P=0.0004)$, although associations between ACT and underweight, normal weight, and overweight patients were not observed (Figure 4).

Additionally, an association between FENO, FEV1 (L), and activin A in overweight subjects was observed $(r=0.51, P=0.003 ; r=-0.65, P<0.0001$, respectively; Figures 5 and 6$)$.

An association between FEV1 (L), peak expiratory flow (mL), and activin A was also observed in all subjects $(\mathrm{r}=-0.48, \mathrm{P}<0.0001 ; \mathrm{r}=-0.42, \mathrm{P}=0.007$, respectively; Figure 7$)$.

Interestingly, although we did not detect an association between sputum eosinophils (\%), sputum neutrophils (\%), or sputum macrophages (\%), we observed a much higher percentage of sputum lymphocytes (\%) in the underweight group than in other groups $(\mathrm{P}<0.0001$; Figure 8).

We attempted to measure airway thickness on HRCT as a marker of remodeling (included patients were 36). Although no differences between groups were found in wall thickness (BWT) $(\mathrm{P}=0.31)$, a significant difference between groups was found in WA $(\%)(\mathrm{P}$ $<0.0001)$. A correlation between BWT and activin A was found in underweight patients $(\mathrm{r}=$ $0.67, \mathrm{P}=0.48)$ and normal weight patients $(\mathrm{r}=0.51, \mathrm{P}=0.042$; Figure 9$)$.

\begin{tabular}{lcccc}
\multicolumn{1}{c}{ Table 1. Clinical data. } & \multicolumn{3}{c}{} \\
\hline Groups & Underweight & Normal weight & Overweight & P value \\
\hline $\mathrm{N}$ & 24 & 40 & 30 & - \\
Female (male) & $18(6)$ & $32(8)$ & $18(12)$ & - \\
Age (years) & $49.5(12.89)$ & $46.00(11.04)$ & $46.87(9.54)$ & NS \\
BMI & $17.44(1.20)$ & $22.31(1.58)$ & $29.31(2.87)$ & $<0.0001$ \\
Delay treatment (years) & $23.75(18.19)$ & $10.83(15.47)$ & $20.47(19.83)$ & 0.16 \\
Disease duration (years) & $24.00(17.85)$ & $15.33(15.82)$ & $23.40(19.66)$ & 0.33 \\
ACT scores & $12.75(3.01)$ & $17.13(4.17)$ & $17.53(3.10)$ & $<0.0001$ \\
IgE & $208.7(147.7)$ & $105.4(169.2)$ & $202.3(292.7)$ & 0.07 \\
Allergic rhinitis (N) & 6 & 18 & 5 & - \\
Best FEV1 (L predicted) & $0.93(0.59)$ & $1.51(0.75)$ & $1.51(0.81)$ & 0.005 \\
Best FEV1 (\% predicted) & $42.75(20.85)$ & $60.33(23.66)$ & $66.53(19.96)$ & 0.0005 \\
FEV1/FVC (\%) & $66.50(16.57)$ & $64.97(15.44)$ & $64.23(12.84)$ & NS \\
PEF & $147.8(87.47)$ & $201.5(116.1)$ & $302.0(147.2)$ & 0.038 \\
FENO (ppb)* & $90.00(3.1)$ & $47.00(52.2)$ & $40.62(15.38)$ & $<0.0001$ \\
Sputum eosinophils (\%) & $12.54(25.04)$ & $14.59(20.22)$ & $21.00(20.41)$ & 0.19 \\
Sputum neutrophils (\%) & $72.04(23.92)$ & $73.60(24.90)$ & $63.43(23.49)$ & 0.41 \\
Sputum macrophages (\%) & $3.66(5.10)$ & $5.97(8.76)$ & $8.84(17.64)$ & 0.35 \\
Sputum lymphocytes (\%) & $12.31(13.14)$ & $3.00(2.83)$ & $1.72(1.41)$ & $<0.0001$ \\
Exacerbations in the past 2 years & $1.50(1.53)$ & $1.06(2.91)$ & $4.06(7.04)$ & 0.027 \\
Hospital & $0.17(0.38)$ & $1.97(4.48)$ & $2.20(6.20)$ & $<0.0001$ \\
\hline Values are reporter & & & & \\
\end{tabular}

Values are reported as means (SD) unless otherwise stated.*Kruskal-Wallis test is presented. NS = not significant. 

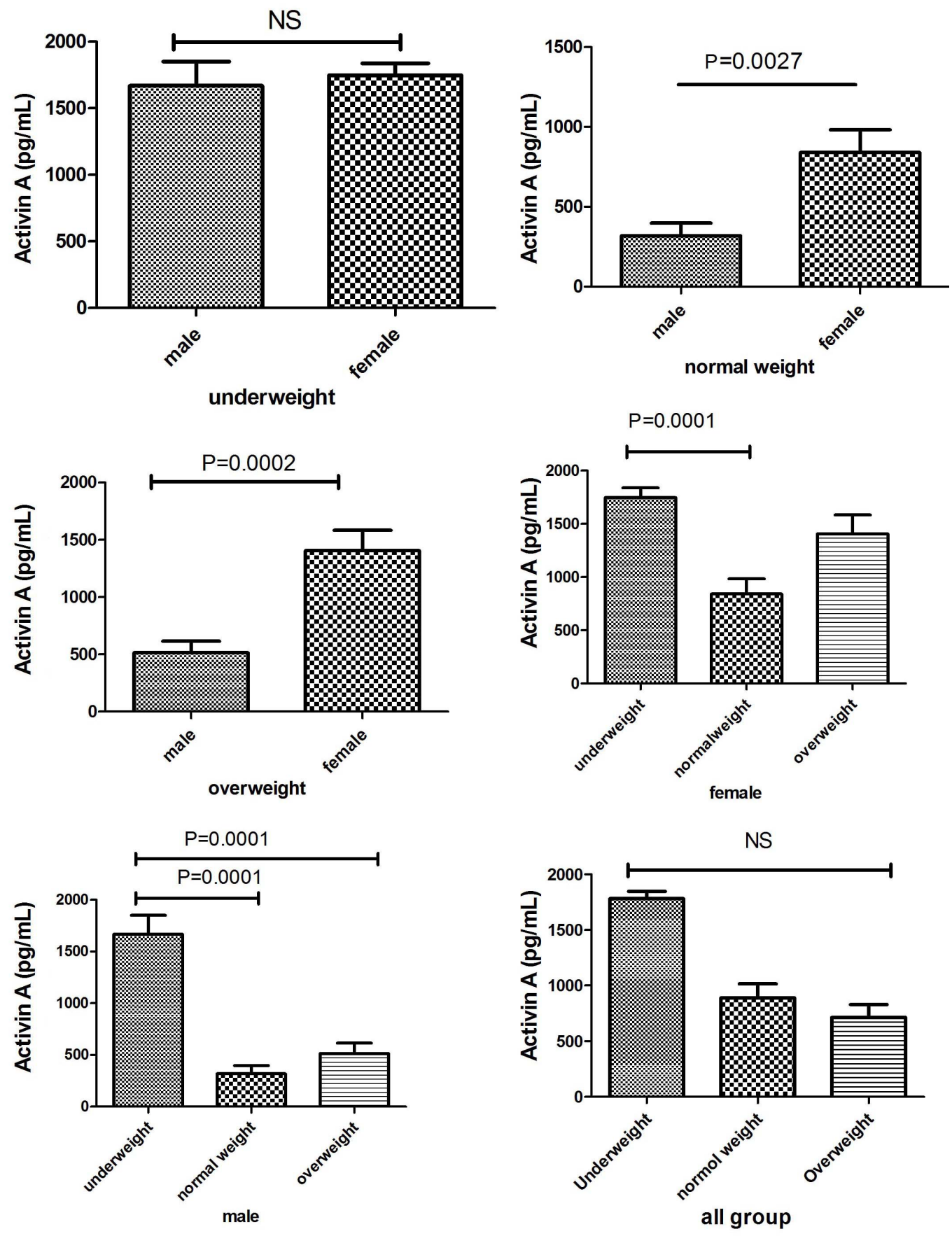

Figure 1. Comparison of serum levels of activin A in underweight, normal weight, and overweight patients by gender. The results are reported as one-way analysis of variance. NS = not significant. 

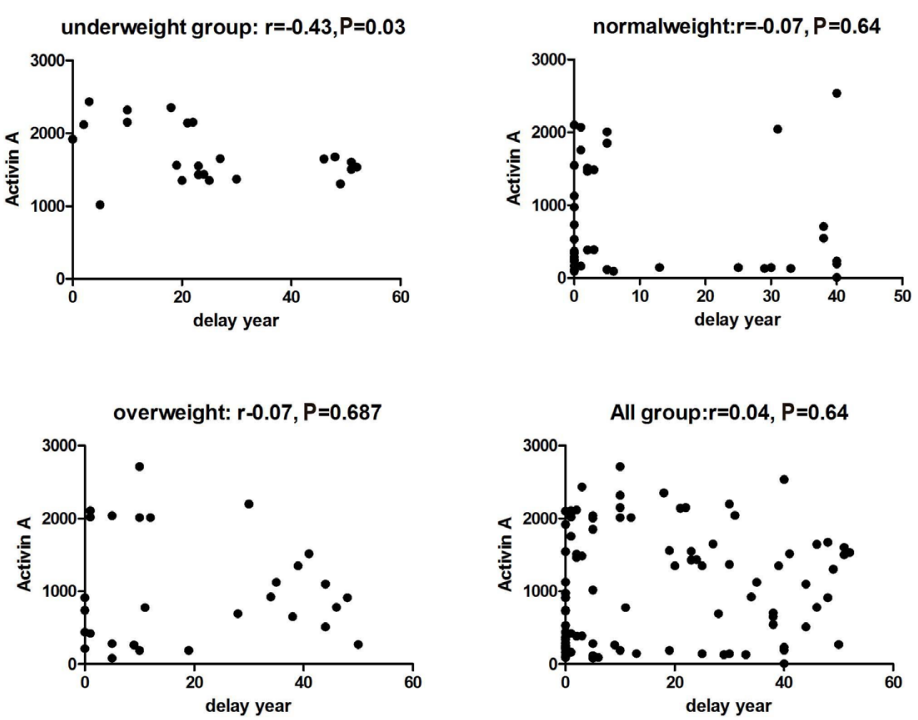

Figure 2. Associations between activin A levels and delayed treatment years among underweight, normal weight, and overweight patients.
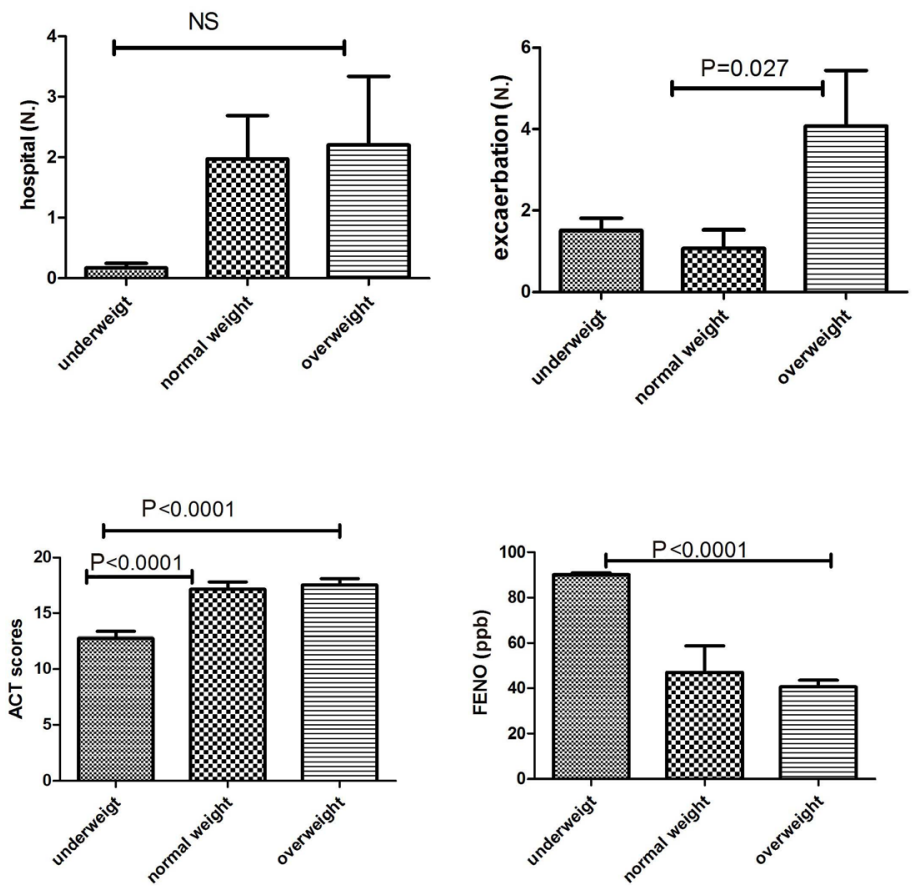

Figure 3. Comparison of hospital admissions in the past 2 years, exacerbations in the past 2 years, asthma control test scores, and FENO in underweight, normal weight, and overweight patients. The results are reported as one-way analysis of variance. $\mathrm{NS}=$ not significant. 

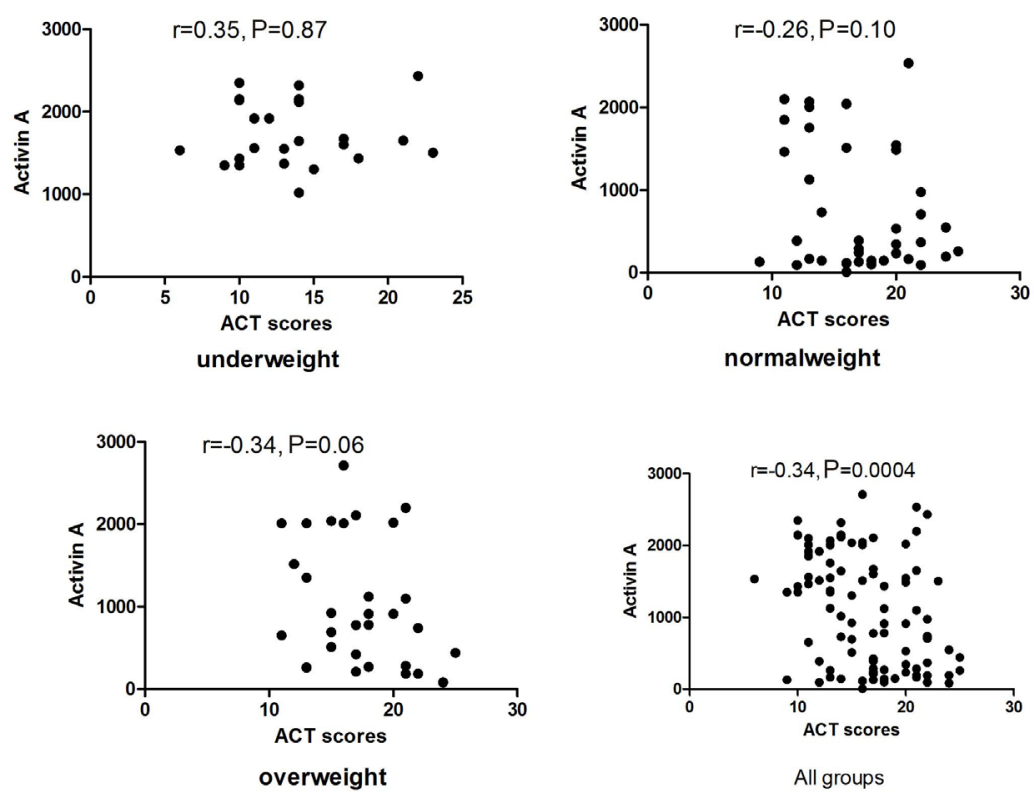

Figure 4. Associations between activin A levels and asthma control test scores among underweight, normal weight, and overweight patients.
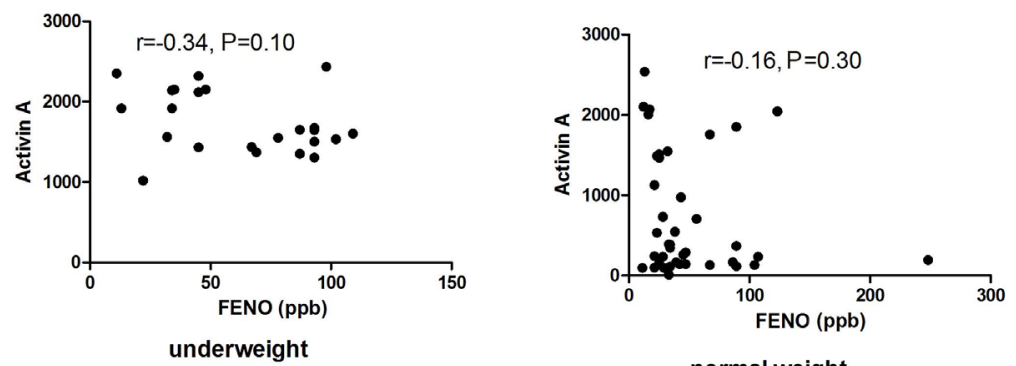

normal weight
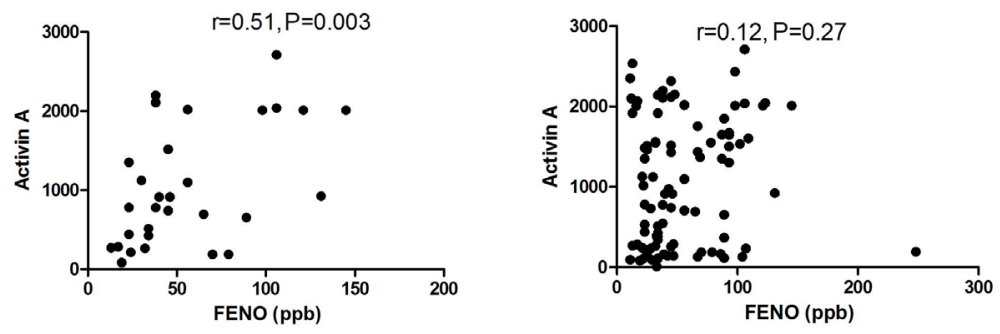

overweight

all group

Figure 5. Associations between activin A levels and FENO (ppb) among underweight, normal weight, and overweight patients. 

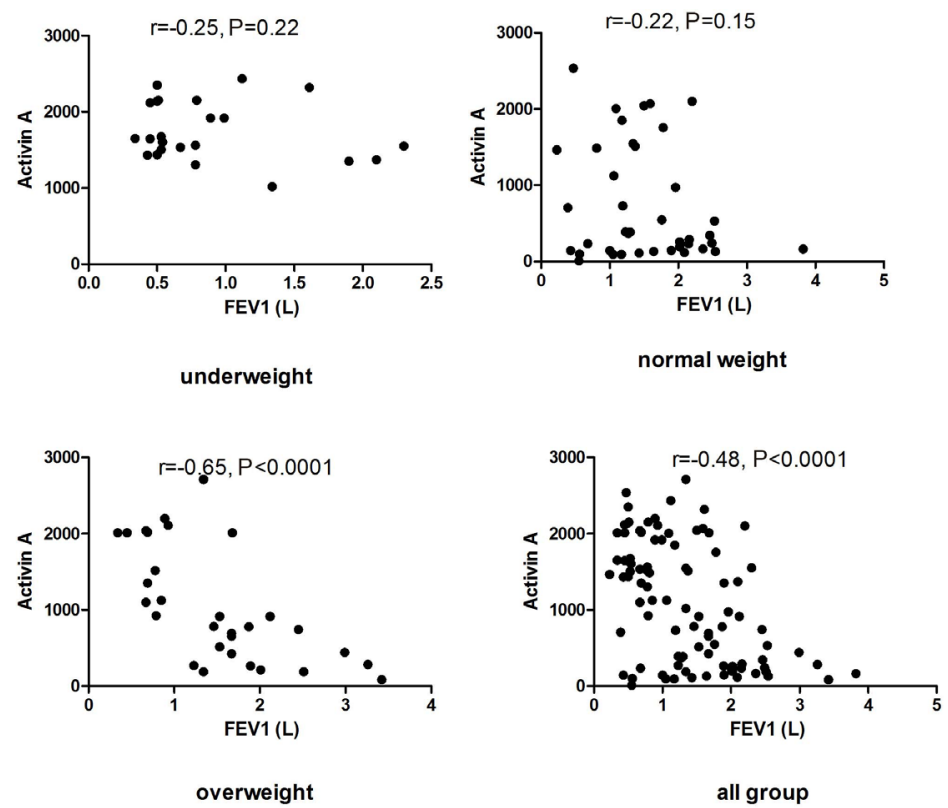

Figure 6. Associations between activin A levels and FEV1 (L) among underweight, normal weight, and overweight patients.

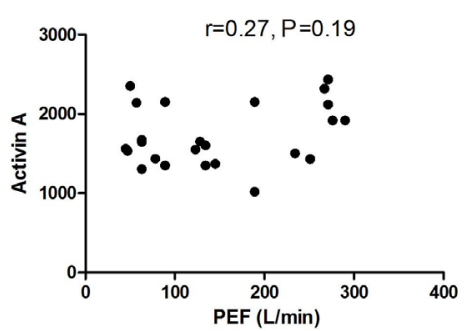

underweight

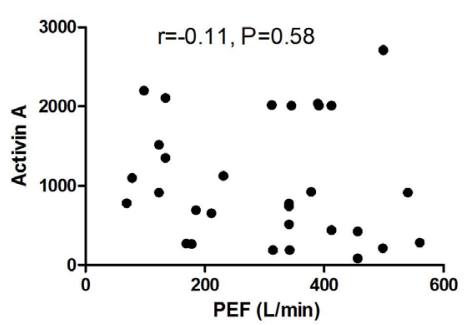

overweight

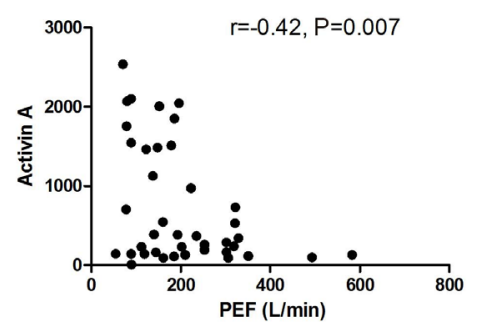

normal weight

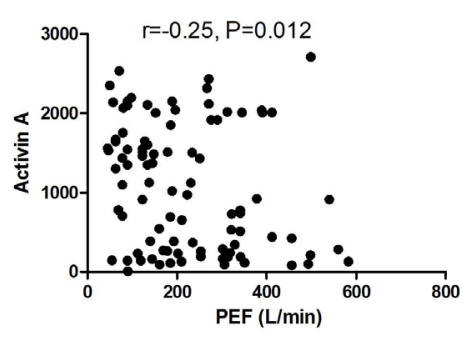

All group

Figure 7. Associations between activin A levels and PEF $(\mathrm{mL})$ among underweight, normal weight, and overweight patients. 

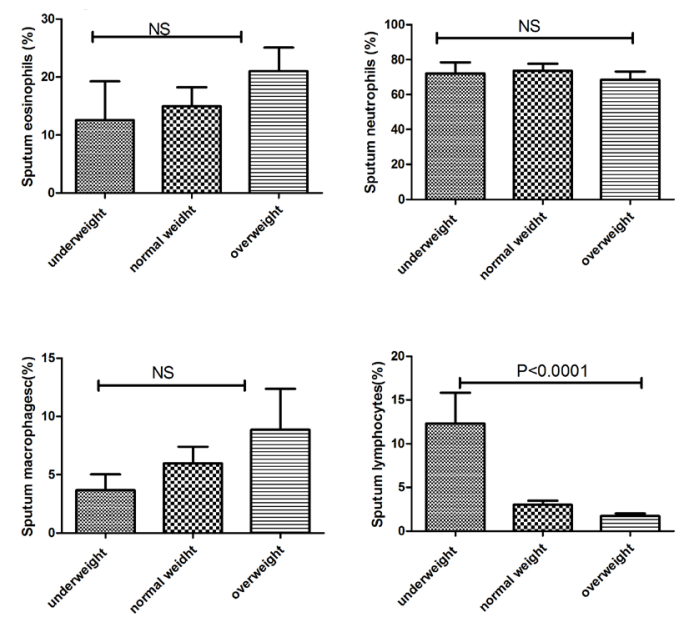

Figure 8. Comparison of sputum lymphocytes (\%), sputum eosinophils (\%), sputum neutrophils (\%), and sputum macrophages (\%) with underweight, normal weight, and overweight patients. The results are reported as one-way analysis of variance. NS: Not significant.

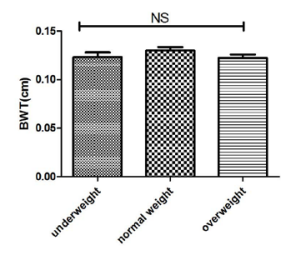

$r=0.67, P=0.048$

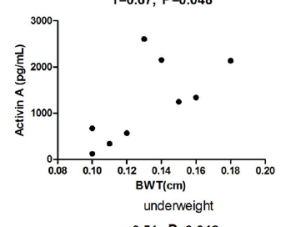

$r=0.51, P=0.042$

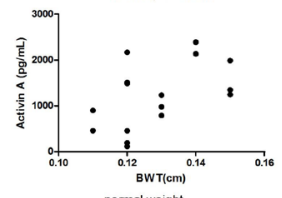

normal weight

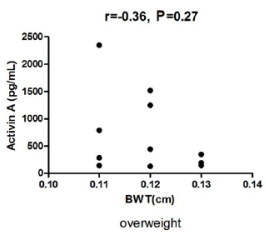

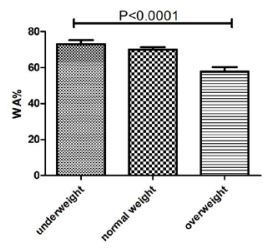

$r=0.51, P=0.16$
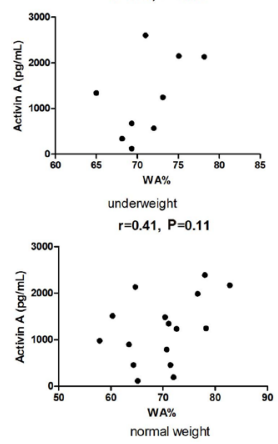

$1=0.27, P=0.42$

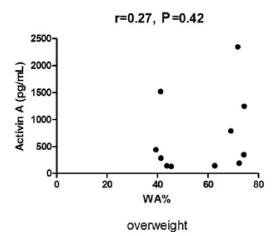

Figure 9. Nine underweight asthmatic patients, 15 normal weight, and 11 overweight patients fulfilled the inclusion criteria. Comparison of BWT $(\mathrm{cm})$ (a measure of airway wall thickness on HRCT, see Methods section for details) and WA $(\%)$ with underweight $(\mathrm{N}=9)$, normal weight $(\mathrm{N}=19)$, and overweight patients $(\mathrm{N}=11)$. The results are reported as one-way analysis of variance. Correlation between BWT (cm), WA (\%), and activin A level in underweight, normal weight, and overweight patients including 36 subjects who underwent HRCT. NS = not significant. 


\section{DISCUSSION}

In the present study, we found that in asthmatic patients, with respect to BMI, serum activin A levels differed in underweight, normal weight, and overweight asthma patients. This is the first study to demonstrate that activin A serum levels were increased in underweight and overweight asthma patients by gender. We also found an association between activin $\mathrm{A}$ and BWT and WA\% of HRCT, FENO, asthma control test scores, FEV1 (L), and cells of induced sputum in underweight and overweight asthma patients.

A recently published study showed that activin A expression was significantly increased in the bronchial tissue of asthmatics, particularly in the sub-epithelium of severe asthma patients, and that activin A was primarily expressed by infiltrating mast cells, neutrophils, macrophages, and smooth muscle cells. Activin A receptors were colocalized in endothelial cells, particularly in severe asthma, and was correlated with angiogenesis and disease severity (Tousa et al., 2012). Activin A has been implicated in airway inflammation in mouse models of allergen challenge (Rosendahl et al., 2002), was elevated in the serum of symptomatic patients with asthma, and was detected in peripheral blood $\mathrm{T}$ helper type 2 cells from patients with asthma (Kariyawasam et al., 2009).

In our study, we examined Chinese patients, and thus a large number of underweight patients were included in the study. We previously found that activin A may be a marker of airway remodeling (unpublished results). Obesity appears to be a risk factor for both airway remodeling and asthma (Shore and Fredberg, 2005; Shore, 2008). Litonjua et al. (Litonjua et al., 2002) reported an association between increased BMI and onset of airway hyper-responsiveness in a longitudinal study of aging in male subjects in the United States. Thus, we designed this study to determine whether a relationship exists between activin A and BMI. Although the results showed that activin A was increased in the overweight group, activin A was increased in underweight patients to a much higher extent. This result may have been related to gender. Methods for noninvasive assessment of airway remodeling remain limited. We used HRCT to measure airway thickness as a marker of remodeling. Differences between groups and a correlation between wall thickness and activin A were observed. Although the power for detecting this difference was low in our study, these findings are consistent with the findings of Gupta et al. (2009). The different results regarding HRCT in subjects with asthma may have been due to the different patient populations sampled, disease duration, treatment history, and different measurement techniques.

Activin $\mathrm{A}$ is a pleiotropic cytokine that belongs to the transforming growth factor- $\beta$ superfamily and plays a critical role in important biological processes. Increases in serum tumor necrosis factor- $\alpha$ in airway smooth muscle in obese patients were found to be very interesting. Tumor necrosis factor receptors are expressed on airway smooth muscle, and exogenous tumor necrosis factor- $\alpha$ has been shown to increase the in vitro contractility of mouse airways to a variety of contractile agonists (Chen et al., 2003). Because airway smooth muscle is a key end effector of acute airway narrowing, obesity might influence airway smooth muscle function and airway responsiveness. In this study, we found that cells of induced sputum, particularly sputum neutrophils, which were increased during airway remodeling of asthma, were unrelated to activin A levels (except for sputum lymphocytes).

Limitations of our study were that patients were of a wide age range and that gender bias may have existed. Asthma is more prevalent in females than in males, so it was not surprising that there were more female subjects than male subjects in our study. Additionally, this 
study was performed in a specialty clinical sample; patients without asthma were included, but we did not include a healthy control group. Our sample size was also very small, and future studies involving a larger number of subjects should be conducted to verify our conclusions.

In summary, activin $\mathrm{A}$ is an important contributing factor to asthma in underweight and overweight asthma patients. Activin A may be involved in the pathogenesis of asthma in underweight and overweight asthma patients.

\section{ACKNOWLEDGMENTS}

We thank Zhang Lanlan for her assistance with preparing the manuscript, data analysis, data collection, and figure preparation.

\section{REFERENCES}

American Thoracic Society (ATS) (1987). Standards for the diagnosis and care of patients with chronic obstructive pulmonary disease (COPD) and asthma. This official statement of the American Thoracic Society was adopted by the ATS Board of Directors, November 1986. Am. Rev. Respir. Dis. 136: 225-244.

Beckett WS, Jacobs DR Jr, Yu X, Iribarren C, et al. (2001). Asthma is associated with weight gain in females but not males, independent of physical activity. Am. J. Respir. Crit. Care Med. 164: 2045-2050.

Beuther DA, Weiss ST and Sutherland ER (2006). Obesity and asthma. Am. J. Respir. Crit. Care Med. 174: 112-119.

Chen H, Tliba O, Van Besien CR, Panettieri RA Jr, et al. (2003). TNF-[alpha] modulates murine tracheal rings responsiveness to G-protein-coupled receptor agonists and KCl. J. Appl. Physiol. 95: 864-872.

Chen Y, Dales R, Krewski D and Breithaupt K (1999). Increased effects of smoking and obesity on asthma among female Canadians: the National Population Health Survey, 1994-1995. Am. J. Epidemiol. 150: 255-262.

Flegal KM, Carroll MD, Ogden CL and Johnson CL (2002). Prevalence and trends in obesity among US adults, 19992000. JAMA 288: 1723-1727.

Guerra S, Sherrill DL, Bobadilla A, Martinez FD, et al. (2002). The relation of body mass index to asthma, chronic bronchitis, and emphysema. Chest 122: 1256-1263.

Gupta S, Siddiqui P, Haldar JV, Raj JJ, et al. (2009). Qualitative analysis of high-resolution CT scans in severe asthma, CHEST J. 136:1521-1528.

Hedley AA, Ogden CL, Johnson CL, Carroll MD, et al. (2004). Prevalence of overweight and obesity among US children, adolescents, and adults, 1999-2002. JAMA 291: 2847-2850.

NHLBI (1998) Obesity Education Initiative Expert Panel on the Identification, Evaluation, and Treatment of Obesity in Adults (US). Clinical guidelines on the identification, evaluation, and treatment of overweight and obesity in adults. National Heart, Lung, and Blood Institute, Bethesda.

Jones KL, Mansell A, Patella S, Scott BJ, et al. (2007). Activin A is a critical component of the inflammatory response, and its binding protein, follistatin, reduces mortality in endotoxemia. Proc. Natl. Acad. Sci. U. S. A. 104: 16239-16244.

Kariyawasam HH, Pegorier S, Barkans J, Xanthou G, et al. (2009). Activin and transforming growth factor-beta signaling pathways are activated after allergen challenge in mild asthma. J. Allergy Clin. Immunol. 124: 454-462.

Kasahara K, Shiba K, Ozawa T, Okuda K, et al. (2002). Correlation between the bronchial subepithelial layer and whole airway wall thickness in patients with asthma. Thorax 57: 242-246.

King GG, Müller NL, Whittall KP, Xiang QS, et al. (2000). An analysis algorithm for measuring airway lumen and wall areas from high-resolution computed tomographic data. Am. J. Respir. Crit. Care Med. 161: 574-580.

Litonjua AA, Sparrow D, Celedon JC, DeMolles D, et al. (2002). Association of body mass index with the development of methacholine airway hyperresponsiveness in men: the Normative Aging Study. Thorax 57: 581-585.

Miller MR, Hankinson J, Brusasco V, Burgos F, et al. (2005). Standardisation of spirometry. Eur. Respir. J. 26: 319-338.

Pavord ID, Pizzichini MM, Pizzichini E and Hargreave FE (1997). The use of induced sputum to investigate airway inflammation. Thorax 52: 498-501.

Pleis JR, Lucas JW and Ward BW (2009). Summary health statistics for US adults: National Health Interview Survey, 2008. Vital Health Stat. 1-157.

Rosendahl A, Pardali E, Speletas M, Ten Dijke P, et al. (2002). Activation of bone morphogenetic protein/Smad signaling in bronchial epithelial cells during airway inflammation. Am. J. Respir. Cell Mol. Biol. 27: 160-169.

Samitas K, Poulos N, Zervas E, Semitekolou M, et al. (2012). Activin-A is crucially involved in airway remodeling and 
angiogenesis in severe asthma. Allergy 67: 591-591.

Shore SA (2008). Obesity and asthma: possible mechanisms. J. Allergy Clin. Immunol. 121: 1087-1093.

Shore SA and Fredberg JJ (2005). Obesity, smooth muscle, and airway hyperresponsiveness. J. Allergy Clin. Immunol. 115: 925-927.

Sulyok S, Wankell M, Alzheimer C and Werner S (2004). Activin: an important regulator of wound repair, fibrosis, and neuroprotection. Mol. Cell. Endocrinol. 225: 127-132.

Tousa S, Semitekolou M, Morianos I, Samitas K, et al. (2012). Activin-A is a critical novel inducer of human regulatory T-cells that control allergic asthma. Allergy 67: 24-24.

Xia Y and Schneyer AL (2009). The biology of activin: recent advances in structure, regulation and function. J. Endocrinol. 202: 1-12. 